\title{
Comparison of pressure-regulated volume control ventilation and pressure control ventilation in patients with abdominal compartment syndrome
}

\author{
JIANGTAO YIN $^{1 *}$, XIN PAN $^{2 *}$, JUE JIA $^{3}$, SHUANGSHUANG SUN ${ }^{1}$ and BING WAN ${ }^{4}$ \\ ${ }^{1}$ Department of Intensive Care Unit, The Affiliated Hospital of Jiangsu University, Zhenjiang, Jiangsu 212001; \\ ${ }^{2}$ Emergency Department, Zhenjiang Emergency Center, Zhenjiang, Jiangsu 212001; ${ }^{3}$ Department of Emergency, The Affiliated \\ Hospital of Jiangsu University, Zhenjiang, Jiangsu 212001; ${ }^{4}$ Department of Respiratory and Critical Care Medicine, \\ The Affiliated Jiangning Hospital of Nanjing Medical University, Nanjing, Jiangsu 210002, P.R. China
}

Received July 11,2018; Accepted November 30, 2018

DOI: $10.3892 /$ etm.2019.7157

\begin{abstract}
Mechanical ventilation support is commonly required in abdominal compartment syndrome (ACS). In the present study, pressure-regulated volume control ventilation (PRVCV) was compared to pressure control ventilation (PCV) in patients with ACS. The prospective study included 40 patients with ACS who were randomized into the PCV or PRVCV groups and subjected to the different modes of ventilation. After $6 \mathrm{~h}$ of ventilation, arterial blood gas, respiratory mechanics and hemodynamics parameters, as well as the intra-abdominal pressure (IAP) and Sequential Organ Failure Assessment (SOFA) scores were calculated. Compared to the PCV mode, mechanical ventilation with PRVCV lead to a significant decrease in the partial pressure of carbon dioxide, the peak inspiratory pressure, the mean inspiratory pressure, the central venous pressure, the heart rate and the extravascular lung water index. In addition, a marked improvement in $\mathrm{pH}$, partial pressure of oxygen, oxygenation index and pulmonary static compliance was noted. However, no significant differences in airway resistance, mean arterial pressure, or IAP and SOFA scores were obtained. In conclusion, the PRVCV mode is better than the PCV mode in ventilation patients with ACS, and should therefore be used as a lung protective strategy. The present study was registered at Chictr.org (no. ChiCTR1800016869).
\end{abstract}

Correspondence to: Dr Bing Wan, Department of Respiratory and Critical Care Medicine, The Affiliated Jiangning Hospital of Nanjing Medical University, 168 Gushan Road, Nanjing, Jiangsu 210002, P.R. China

E-mail: bingwan76@163.com

*Contributed equally

Key words: pressure-regulated volume control ventilation, abdominal compartment syndrome, arterial blood gas, respiratory mechanics, hemodynamics

\section{Introduction}

Intra-abdominal pressure (IAP) is normally atmospheric or sub-atmospheric, and when it exceeds $10 \mathrm{cmH}_{2} \mathrm{O}$, it results in a condition referred to as intra-abdominal hypertension (IAH) (1). The blood flow to and the perfusion pressure of organs in the abdominal cavity decrease with increasing IAP (2). Abdominal compartment syndrome (ACS) refers to organ dysfunction and ischemia resulting from IAH, which triggers a systemic inflammatory response by releasing cytokines, including tumor necrosis factor- $\alpha$, interleukin- 6 and oxygen free radicals. The inflammatory response in turn causes capillary leakage leading to bowel edema, thus further increasing the IAP and resulting in multiple organ dysfunction syndrome. An IAP of $>12 \mathrm{cmH}_{2} \mathrm{O}$ is associated with an increased risk of mortality (3).

The lung is one of the first organs to be damaged due to IAH, since the increased IAP leads to a decreased lung volume and lung compliance, and increased airway resistance, which results in acute respiratory distress syndrome, ultimately requiring mechanical ventilation support (4).

Pressure-regulated volume control ventilation (PRVCV) uses the tidal volume as a feedback control for continuously adjusting the pressure limit (5-7). It enables satisfactory and stable ventilation at the lowest possible pressure level, which reduces injury by positive pressure ventilation and increases safety (8).

Therefore, the objective of the present study was to determine whether the PRVCV mode has a protective effect on patients with ACS compared with pressure control ventilation (PCV).

\section{Materials and methods}

Patients and selection. A prospective study was performed, including consecutive patients hospitalized for $>3$ days at the intensive care unit (ICU) between January 2015 and December 2017. In the current study, 60 patients were enrolled, 20 were excluded, as 18 did not match the inclusion criteria and two refused to be involved. A total of 40 patients $(25$ males 
and 15 females) who matched the diagnostic criteria and managed according to the treatment standards for Abdominal Compartment Syndrome (ACS) of the World Society of the ACS (WSACS) (1), and with the diagnostic criteria for respiratory failure with a partial pressure of oxygen $\left(\mathrm{PaO}_{2}\right)$ of $<60 \mathrm{mmHg}$ or a partial pressure of carbon dioxide $\left(\mathrm{PaCO}_{2}\right)$ of $>50 \mathrm{mmHg}$, were included.

Pediatric patients, patients with lung diseases, including acute exacerbation of chronic obstructive pulmonary disease, severe pneumonia and pulmonary hypertension, and patients with heart diseases, including congenital heart disease, acute coronary syndrome and malignant arrhythmia, were excluded. Patients with severe multiple organ dysfunction, end-stage malignant carcinoma and immunosuppression conditions were also excluded.

IAH is divided into 4 stages according to the IAP: Stage I, 12-15 mmHg; stage II, 16-20 mmHg; stage III, 21-25 mmHg; and stage VI, >25 mmHg. ACS is defined as a sustained IAP at $>20 \mathrm{mmHg}$, with or without an abdominal perfusion pressure of $<60 \mathrm{mmHg}$, which is consistent with the definition of organ dysfunction/failure published in 2013 by the WSACS (1). The IAP was measured every $6 \mathrm{~h}$ and patients were required to have stable hemodynamics for $>12 \mathrm{~h}$. Therefore, their mean arterial pressure (MAP) was maintained at $>60 \mathrm{mmHg}$ by continuous intravenous administration of vasoactive drugs. In the present study, the sedation score on the Sedation-Agitation Scale was maintained between 3 and 4 using a sedative (9). The patients were randomized into two groups: i) In the PCV group, patients were ventilated using the PCV mode with an inspiratory pressure of $8-15 \mathrm{mmHg}$, inspiratory time of $0.8-1.2 \mathrm{sec}$, inhaled gas oxygen concentration [fraction of inspired oxygen $\left(\mathrm{FiO}_{2}\right)$ ] of 0.3-0.6 and positive end expiratory pressure (PEEP) of 6-12 $\mathrm{mmHg}$; and ii) in the PRVCV group, patients were ventilated using the PRVCV mode with a tidal volume of $5-12 \mathrm{ml} / \mathrm{kg}$, respiratory rate of $12-18$ times per minute, upper pressure limit $\left(\mathrm{P}_{\max }\right)$ of $35 \mathrm{mmHg}$, inspiratory:expiratory of $1: 2, \mathrm{FiO}_{2}$ of $0.3-0.6$ and PEEP of 6-12 mmHg. Parameters were adjusted based on disease severity, lung compliance and arterial blood gas (ABG), in order to maintain an oxygen saturation of $90-95 \%$.

Conventional and active ICU management included disinfection, fasting, gastrointestinal decompression, abdominal drainage and correction of any electrolyte imbalances. All patients required invasive mechanical ventilation; the Dräger Evita 4 ventilator (Drägerwerk AG \& Co. KGaA, Lübeck, Germany) was used for the PCV group and the MAQUET Servo-i ventilator (MAQUET Ltd., Tyne \& Wear, UK) for the PRVCV group.

Measurement of IAP. The IAP was measured in the urinary bladder by using a Foley Manometer device with the patient in a supine position (10). The bladder was first emptied of intra-vesical urine and then injected with $50 \mathrm{ml}$ saline through a catheter. Using the symphysis pubis as a zero-reference point, the end expiration pressure was measured. A measurement protocol was drafted and performed by experienced staff.

Data collection. ABG parameters, including $\mathrm{pH}, \mathrm{PaO}_{2}$, $\mathrm{PaCO}_{2}$ and oxygenation index $\left(\mathrm{PaO}_{2} / \mathrm{FiO}_{2}\right)$, were recorded. Respiratory mechanics indices, including peak inspiratory pressure $(\mathrm{PIP})$, mean inspiratory pressure $\left(\mathrm{P}_{\text {mean }}\right)$, pulmonary static compliance (Cst) and airway resistance $(\mathrm{R})$ were monitored by a detection system in the ventilator. Hemodynamic values, including the HR, MAP, central venous pressure (CVP) and extravascular lung water index (ELWI) were measured by the $\mathrm{PiCCO}_{2}$ system (Pulsion Co., Glasgow, UK). All data were collected after $6 \mathrm{~h}$ of ventilation and each parameter was measured 3 times.

Statistical analysis. All values are expressed as the mean \pm standard deviation unless otherwise stated and analyzed using SPSS version 19 (IBM Corp., Armonk, NY, USA). Numerical data were compared using Student's unpaired t-test. Categorical data were analyzed with a Chi-square test. $\mathrm{P}<0.05$ was considered to indicate a statistically significant difference.

\section{Results}

Patient characteristics. A total of 60 patients were initially screened, of which 18 did not match the inclusion criteria and 2 refused to participate. The remaining 40 patients completed the weaning procedure (Fig. 1). There were no significant differences between the two groups ( $n=20$ each) in terms of their clinical characteristics (Table I).

Outcomes regarding ABG parameters. All ABG parameters improved following treatment in the two groups (all $\mathrm{P}<0.05$ ). Compared with those obtained using the PCV mode, significant improvements in $\mathrm{pH}(7.33 \pm 0.81$ vs. $7.39 \pm 0.57, \mathrm{P}=0.017), \mathrm{PaO}_{2}$ (75.05 \pm 12.31 vs. $83.50 \pm 15.89 \mathrm{mmHg}, \mathrm{P}=0.012)$ and $\mathrm{PaO}_{2} / \mathrm{FiO}_{2}$ $(169.85 \pm 23.53$ vs. $190.75 \pm 39.72 \mathrm{mmHg}, \mathrm{P}=0.012)$, and a significant decrease in $\mathrm{PaCO}_{2}(46.05 \pm 11.14$ vs. $41.10 \pm 5.68 \mathrm{mmHg}$, $\mathrm{P}=0.039)$ were noted after $6 \mathrm{~h}$ of using the PRVCV mode (Fig. 2).

Outcomes regarding respiratory mechanics. $\mathrm{PIP}, \mathrm{P}_{\text {mean }}$ and Cst were ameliorated following treatment (all $\mathrm{P}<0.05)$. Compared with those obtained using the PCV mode, the PRVCV mode achieved a notably reduced PIP $(23.75 \pm 1.77$ vs. $19.85 \pm 2.70 \mathrm{mmHg}$, $\mathrm{P}=0.008)$ and $\mathrm{P}_{\text {mean }}(12.75 \pm 2.24$ vs. $11.15 \pm 2.03 \mathrm{mmHg}, \mathrm{P}=0.043)$, and an increased Cst $\left(41.35 \pm 4.99\right.$ vs. $45.95 \pm 5.71 \mathrm{ml} / \mathrm{cmH}_{2} \mathrm{O}$, $\mathrm{P}=0.003)$. However, no significant difference was obtained in $\mathrm{R}\left(8.11 \pm 1.38\right.$ vs. $\left.8.06 \pm 1.34 \mathrm{cmH}_{2} \mathrm{O} / \mathrm{l} / \mathrm{sec}, \mathrm{P}>0.05\right)$ between the two groups (Fig. 3).

Outcomes of hemodynamics. HR, CVP and ELWI in the PRVCV and PCV groups were significantly decreased following treatment (all $\mathrm{P}<0.05$ ), and MAP in the PRVCV group was significantly increased following treatment $(\mathrm{P}<0.01)$. Compared with those in the PCV group, the PRVCV group exhibited a significantly decreased CVP $(17.70 \pm 3.50$ vs. $15.15 \pm 3.13 \mathrm{mmHg}, \mathrm{P}=0.037)$, ELWI $(9.35 \pm 1.27$ vs. $7.75 \pm 2.49 \mathrm{ml} / \mathrm{kg}, \mathrm{P}=0.012)$ and $\mathrm{HR}(99.65 \pm 9.76$ vs. $92.60 \pm 8.17$ beats $/ \mathrm{min}, \mathrm{P}=0.036)$, while the MAP was not significantly different $(70.00 \pm 8.38$ vs. $71.30 \pm 6.13 \mathrm{~mm} \mathrm{Hg}$, $\mathrm{P}=0.594$; Fig. 4).

Outcomes regarding IAP and SOFA scores. No significant differences in IAP $(22.55 \pm 2.28$ vs. $21.60 \pm 2.19 \mathrm{mmHg}$, 
Table I. Baseline characteristics of the study groups.

\begin{tabular}{|c|c|c|c|c|}
\hline Characteristic & Normal value & PCV group $(n=20)$ & PRVCV group $(n=20)$ & P-value \\
\hline Age (years) & & $67.05 \pm 10.85$ & $58.55 \pm 15.39$ & 0.051 \\
\hline $\operatorname{Sex}(M / F)$ & & $13 / 7$ & $12 / 8$ & 0.833 \\
\hline Height $(\mathrm{cm})$ & & $167.00 \pm 6.59$ & $166.15 \pm 7.05$ & 0.696 \\
\hline Weight (kg) & & $62.80 \pm 5.91$ & $63.80 \pm 8.05$ & 0.657 \\
\hline BMI $\left(\mathrm{kg} / \mathrm{m}^{2}\right)$ & $18.50-25$ & $21.80 \pm 2.26$ & $21.15 \pm 1.66$ & 0.307 \\
\hline $\mathrm{IAP}(\mathrm{mmHg})$ & $5-7$ & $23.40 \pm 2.37$ & $24.20 \pm 2.86$ & 0.341 \\
\hline SOFA & 0 & $17.10 \pm 2.10$ & $16.75 \pm 1.55$ & 0.552 \\
\hline $\mathrm{pH}$ & $7.35-7.45$ & $7.24 \pm 0.08$ & $7.29 \pm 0.09$ & 0.071 \\
\hline $\mathrm{PaO}_{2}(\mathrm{mmHg})$ & $60-90$ & $65.40 \pm 4.01$ & $64.40 \pm 3.63$ & 0.762 \\
\hline $\mathrm{PaCO}_{2}(\mathrm{mmHg})$ & $35-45$ & $51.00 \pm 7.22$ & $49.20 \pm 3.75$ & 0.448 \\
\hline $\mathrm{PaO}_{2} / \mathrm{FiO}_{2}(\mathrm{mmHg})$ & $400-500$ & $146.15 \pm 16.42$ & $148.35 \pm 16.10$ & 0.788 \\
\hline PIP $(\mathrm{mmHg})$ & $7-12$ & $27.00 \pm 4.54$ & $26.85 \pm 7.23$ & 0.917 \\
\hline $\mathrm{P}_{\text {mean }}(\mathrm{mmHg})$ & $4-11$ & $14.65 \pm 2.60$ & $15.30 \pm 2.85$ & 0.405 \\
\hline Cst $\left(\mathrm{ml} / \mathrm{cmH}_{2} \mathrm{O}\right)$ & $60-100$ & $37.35 \pm 3.51$ & $36.90 \pm 4.48$ & 0.765 \\
\hline $\mathrm{R}\left(\mathrm{cmH}_{2} \mathrm{O} / 1 / \mathrm{sec}\right)$ & $1-3$ & $7.96 \pm 1.39$ & $8.05 \pm 1.43$ & 0.829 \\
\hline HR (beats/min) & $60-100$ & $107.70 \pm 9.31$ & $111.95 \pm 13.73$ & 0.203 \\
\hline MAP (mmHg) & $70-105$ & $65.90 \pm 8.26$ & $63.45 \pm 7.74$ & 0.316 \\
\hline $\mathrm{CVP}(\mathrm{mmHg})$ & $4-9$ & $20.90 \pm 4.01$ & $22.60 \pm 4.43$ & 0.182 \\
\hline ELWI $(\mathrm{ml} / \mathrm{kg})$ & $3-7$ & $12.00 \pm 2.07$ & $12.05 \pm 1.82$ & 0.936 \\
\hline \multicolumn{5}{|l|}{ Etiology } \\
\hline Intestinal obstruction/necrosis & & $6(30)$ & $10(50)$ & 0.333 \\
\hline Severe multiple trauma & & $7(35)$ & $4(20)$ & 0.480 \\
\hline AP & & $3(15)$ & $2(10)$ & 0.999 \\
\hline Septic shock & & $1(5)$ & $2(10)$ & 0.999 \\
\hline Hepatobiliary disease & & $3(15)$ & $2(10)$ & 0.999 \\
\hline
\end{tabular}

Values were expressed as mean \pm standard deviation, range or $\mathrm{n}(\%)$. BMI, body mass index; AP, acute pancreatitis; M, male; F, female; PCV, pressure control ventilation; PRVCV, pressure-regulated volume control ventilation; IAP, intra-abdominal pressure; SOFA, Sequential Organ Failure Assessment; HR, heart rate; MAP, mean arterial pressure; CVP, central venous pressure; ELWI, extravascular lung water index; PIP, peak inspiratory pressure; $\mathrm{P}_{\text {mean }}$, mean inspiratory pressure; Cst, pulmonary static compliance; $\mathrm{R}$, airway resistance; $\mathrm{PaO}_{2}$, partial pressure of $\mathrm{O}_{2} ; \mathrm{PaCO}_{2}$, partial pressure of $\mathrm{CO}_{2} ; \mathrm{FiO}_{2}$, fraction of inspired $\mathrm{O}_{2} ; \mathrm{n} / \mathrm{a}$, not applicable.

$\mathrm{P}=0.222)$ and SOFA scores $(17.55 \pm 1.88$ vs. 16.95 \pm 2.93 , $\mathrm{P}=0.386$ ) were observed between the PRVCV and PCV groups (Fig. 5). However, the IAP was reduced in the two groups following treatment (both $\mathrm{P}<0.05$ ).

\section{Discussion}

ACS is a critical condition requiring mechanical ventilation. In the present study, it was indicated that compared with those in the PCV group, patients that received PRVCV exhibited a significant decrease in respiratory parameters, including $\mathrm{PaCO}_{2}$, airway PIP, $\mathrm{P}_{\text {mean }}, \mathrm{CVP}, \mathrm{HR}$ and ELWI. In addition, significant improvements in $\mathrm{pH}, \mathrm{PaO}_{2}$, oxygenation index and Cst were achieved by using PRVCV as compared to PCV. However, no significant differences were observed in R, MAP, IAP and SOFA scores between the two groups. Thus, PRVCV provides satisfactory and stable ventilation at the lowest possible pressure level, which relieves injury by positive pressure ventilation and increases safety. It is therefore more suitable for patients with ACS, and may be used as a lung protective strategy.
ACS refers to organ dysfunction and ischemia-reperfusion injury resulting from IAH, which may be a consequence of abdominal trauma, intestinal obstruction or severe acute pancreatitis $(11,12)$. ACS affects the normal functioning of the cardiovascular, respiratory and urinary systems. The synergy between these organ systems further increases the IAP, which results in a vicious cycle of organ damage and IAH, finally leading to multiple organ failure (13-15). A recent multi-center prospective study reported that $32.1 \%$ of ICU patients were diagnosed with IAH and $4.2 \%$ with ACS (16). The IAP acts on the diaphragm and constricts the pulmonary segment, leading to alveolar collapse and a decreased ventilation to blood flow ratio, which causes hypoxemia, hypercarbia and ultimately respiratory failure $(17,18)$. Patients with mechanical ventilation and ACS have a higher risk of developing IAH than those without ACS $(19,20)$.

Verzilli et al (21) reported that the fluctuation range of the IAP was lowest when the PEEP was between 6 and $12 \mathrm{mmHg}$ in patients requiring mechanical ventilation. In the present study, the PEEP was maintained between 6 to $12 \mathrm{mmHg}$, since 


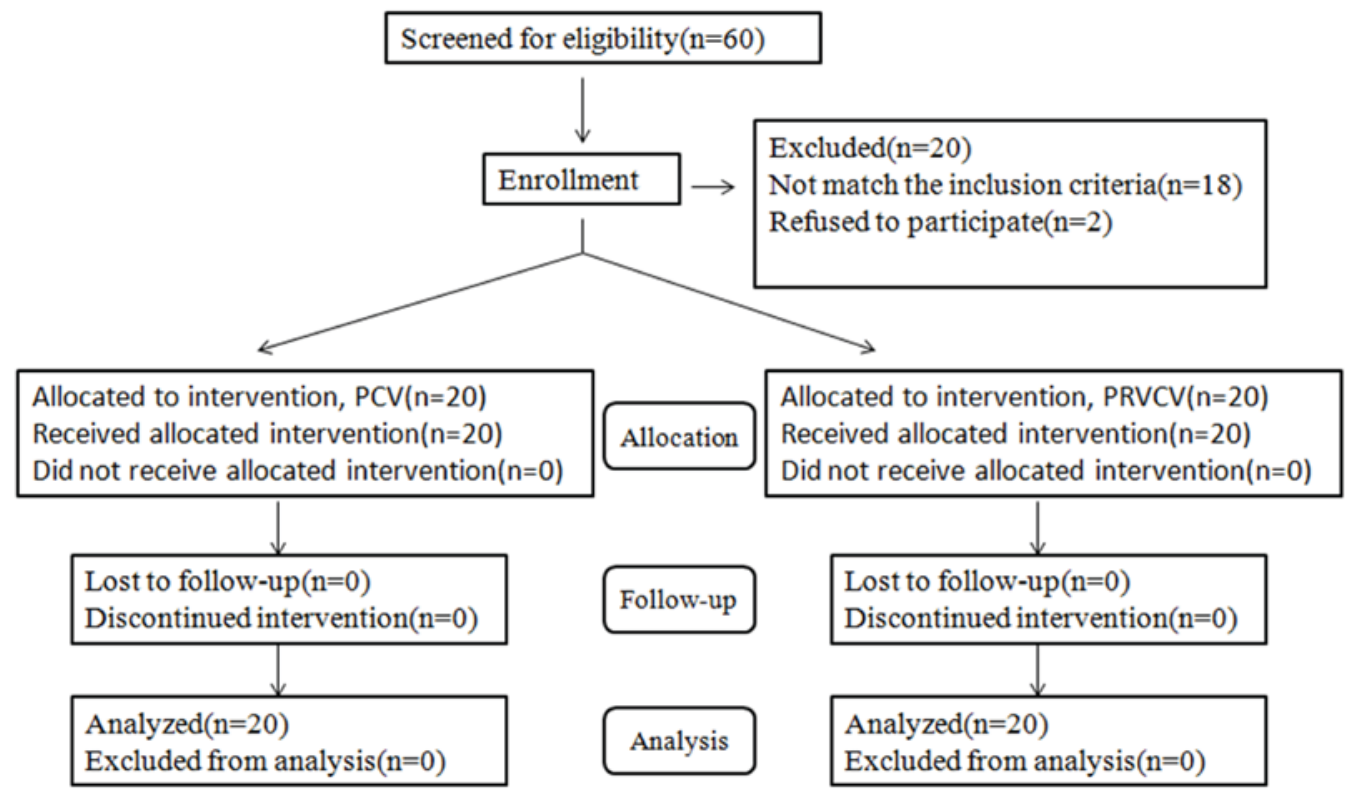

Figure 1. Study flow chart including the randomization of patients to the PRVCV and PCV groups. PCV, pressure control ventilation; PRVCV, pressure-regulated volume control ventilation.
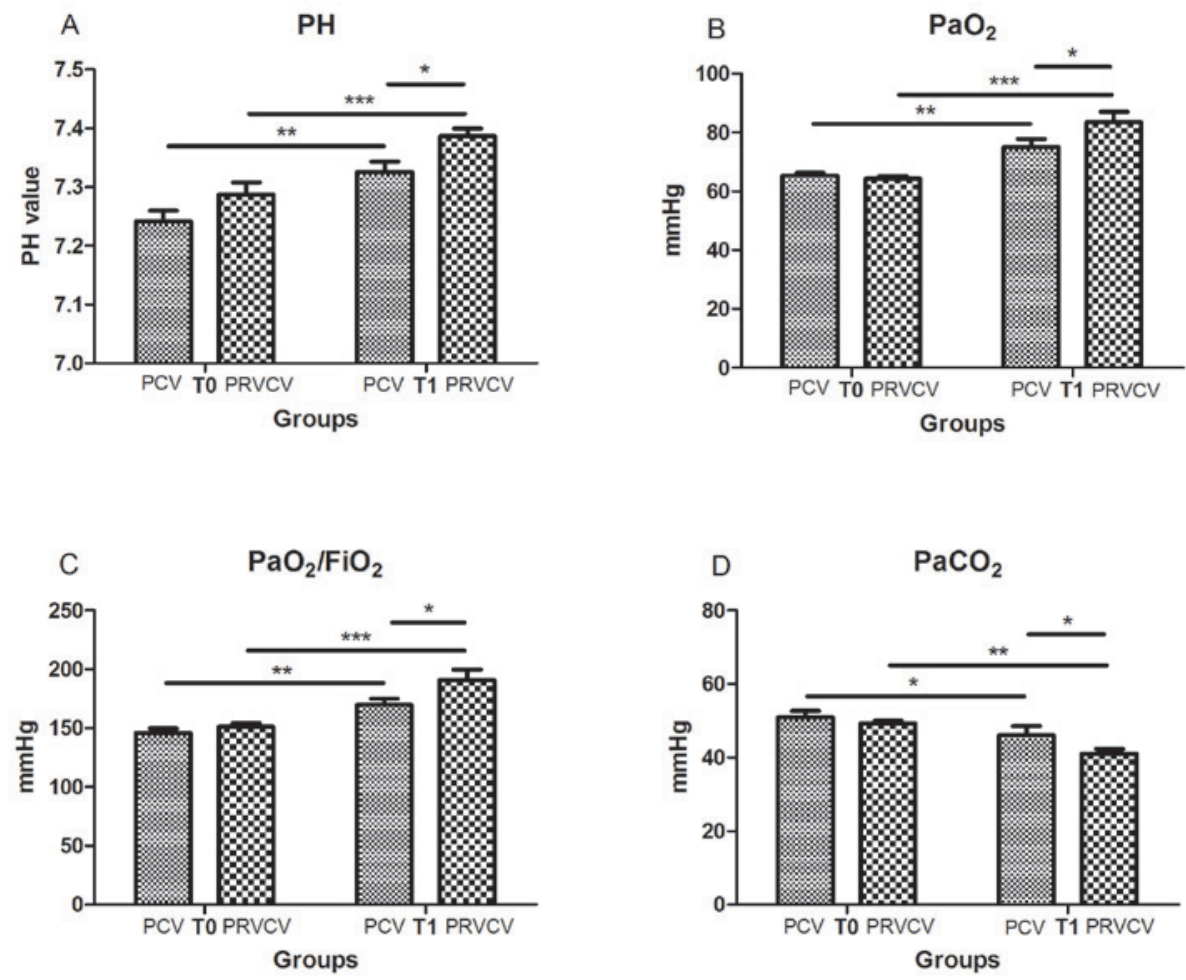

Figure 2. Differences in arterial blood gas parameters between the PRVCV and PCV modes. (A) $\mathrm{pH},(\mathrm{B}) \mathrm{PaO}_{2},(\mathrm{C}) \mathrm{PaO}_{2} / \mathrm{FiO}_{2}$ and $(\mathrm{D}) \mathrm{PaCO}_{2}$. $\mathrm{P}<0.05$, ${ }^{* *} \mathrm{P}<0.01,{ }^{* * *} \mathrm{P}<0.001$. T0, at the beginning of mechanical ventilation; $\mathrm{T} 1,6 \mathrm{~h}$ after ventilation; $\mathrm{PCV}$, pressure control ventilation; PRVCV, pressure-regulated volume control ventilation; $\mathrm{PaO}_{2}$, partial pressure of $\mathrm{O}_{2} ; \mathrm{PaCO}_{2}$, partial pressure of $\mathrm{CO}_{2} ; \mathrm{FiO}_{2}$, fraction of inspired $\mathrm{O}_{2}$.

the optimum PEEP value reduces the extravascular lung water content and improves chest wall compliance. In PCV mode, the pressure is fixed, which results in insufficient ventilatory capacity. Similarly, the ventilatory capacity in the volume control ventilation (VCV) mode is also fixed, but a lack of pressure control further increases the risk of pressure-induced injury. Since an excessive tidal volume results in repeated alveolar folding, the alveolar epithelium and endothelium are frequently deteriorated in patients with IAH.

PRVCV is a dual-control ventilation mode that avoids the high peak airway pressures of volume ventilation, as well as the variation in tidal volume that may occur with pressure ventilation. The compliance of thorax and lung are calculated during the first ventilation, followed by the inspiratory 

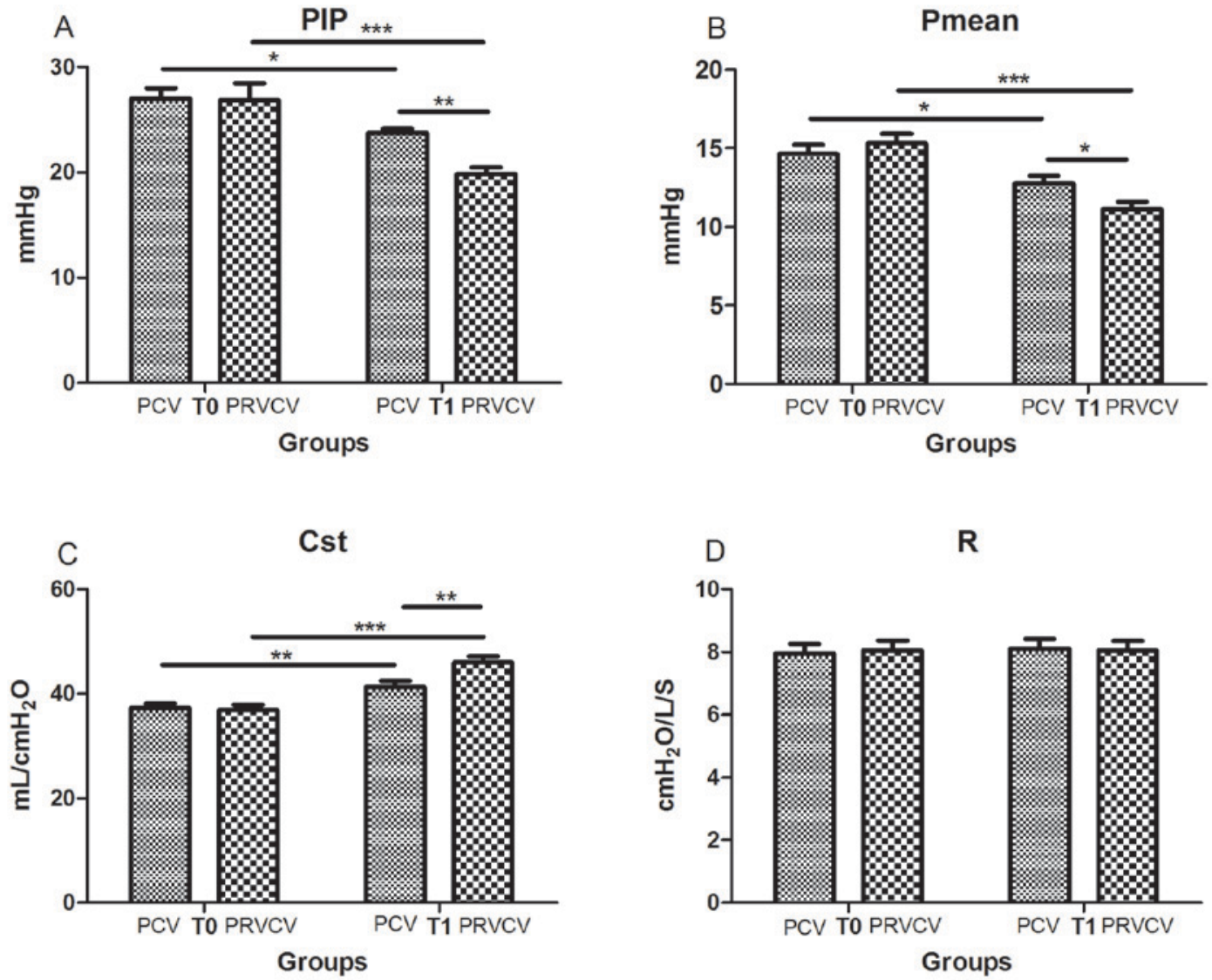

Figure 3. Differences in respiratory mechanics (PIP, $P_{\text {mean }}$, Cst and R) between PRVCV and PCV modes. (A) PIP, (B) $P_{\text {mean }}$, (C) Cst and (D) R. There was no difference between the two groups in $\mathrm{R}$. ${ }^{*} \mathrm{P}<0.05,{ }^{* *} \mathrm{P}<0.01,{ }^{* * * *} \mathrm{P}<0.001$. T0, at the beginning of mechanical ventilation; T1, $6 \mathrm{~h}$ after ventilation; $\mathrm{PCV}$, pressure control ventilation; PRVCV, pressure-regulated volume control ventilation; PIP, peak inspiratory pressure; $\mathrm{P}_{\text {mean }}$, mean inspiratory pressure; Cst, pulmonary static compliance; R, airway resistance.
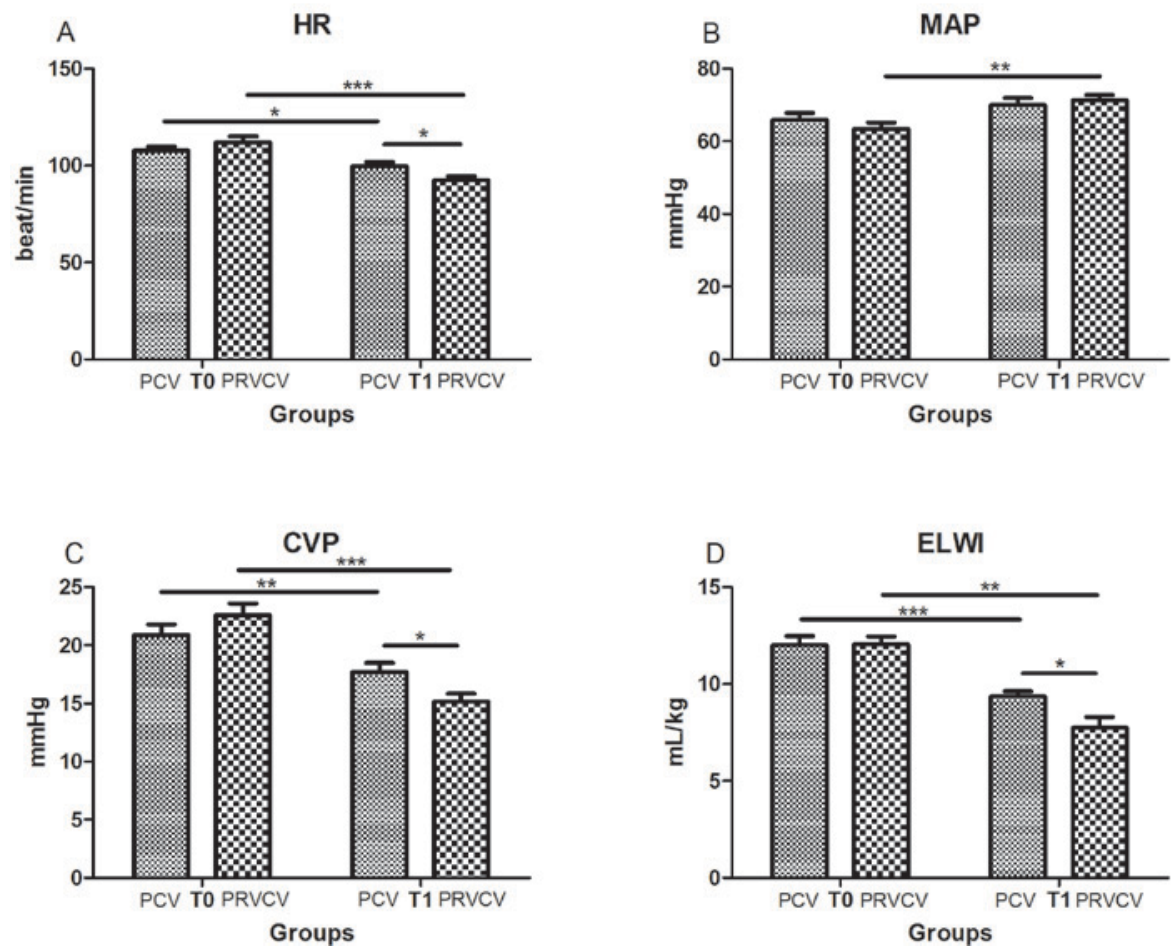

Figure 4. Differences in hemodynamics between PRVCV and PCV modes. (A) HR, (B) MAP, (C) CVP and (D) ELWI. No change was seen in MAP. "P<0.05, ${ }^{* *} \mathrm{P}<0.01,{ }^{* * *} \mathrm{P}<0.001 . \mathrm{T} 0$, at the beginning of mechanical ventilation; T1, $6 \mathrm{~h}$ after ventilation; $\mathrm{PCV}$, pressure control ventilation; PRVCV, pressure-regulated volume control ventilation; HR, heart rate; MAP, mean arterial pressure; CVP, central venous pressure; ELWI, extravascular lung water index. 

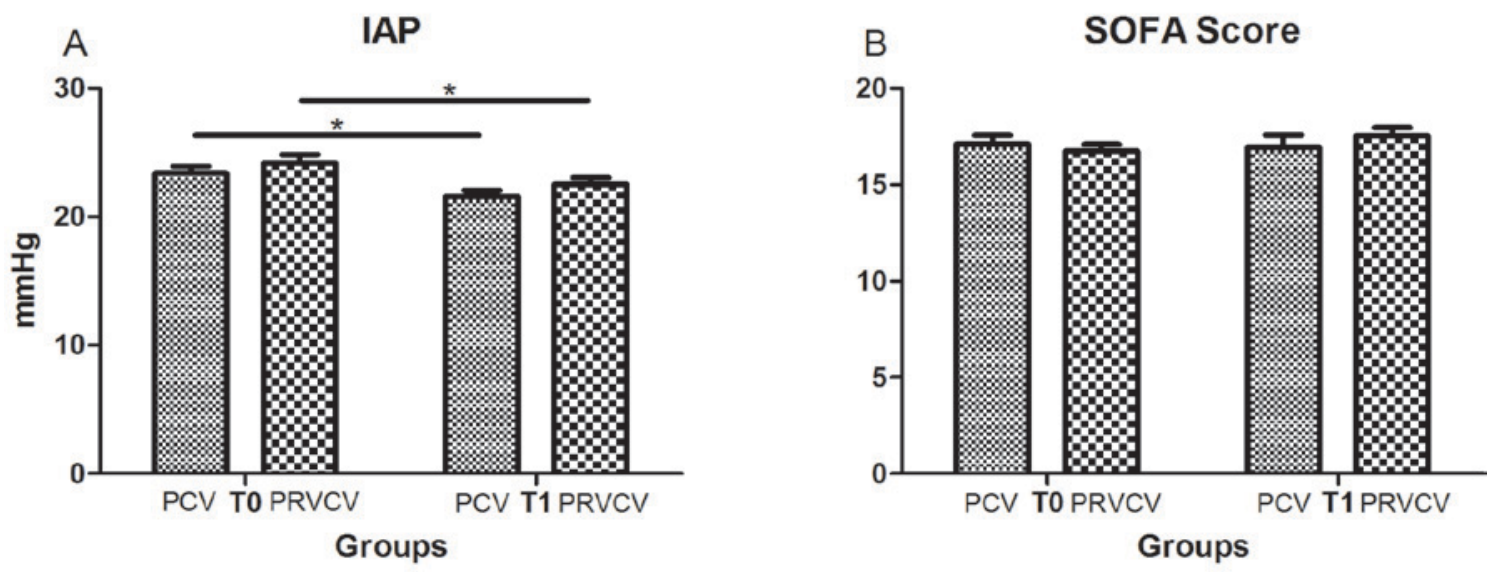

Figure 5. Comparison of IAP and SOFA scores between PRVCV and PCV modes. (A) IAP and (B) SOFA scores. No significant differences were observed ${ }^{*} \mathrm{P}<0.05$. T0, at the beginning of mechanical ventilation; T1, $6 \mathrm{~h}$ after ventilation; PCV, pressure control ventilation; PRVCV, pressure-regulated volume control ventilation; IAP, intra-abdominal pressure; SOFA, Sequential Organ Failure Assessment.

pressure of the preset tidal volume in the next ventilation. The actual inspiratory pressure is $75 \%$ of the expected value, whereas the actual tidal volume is consistent with the preset value (5-7). The ventilator continuously monitors compliance and automatically calculates the association between volume and pressure on the basis of the preset tidal volume. It regulates the next inspiratory pressure level according to anterior monitoring, thereby minimizing the airway pressure. In other words, stable ventilation is provided at the lowest possible ventilation pressure to minimize the chances of bariatric injury due to positive pressure ventilation, and enhance the safety of the treatment. In the present study, the ABG parameters were distinctly improved in the PRVCV mode compared with those in the PCV mode. At the same PEEP level, the oxygenation index was improved and the $\mathrm{PaCO}_{2}$ was significantly declined with PRVCV as compared with PCV.

A great number of pathophysiological changes occur due to IAH, including an increase in thoracic pressure and CVP, a decrease in the returned blood volume and a compensatory increase in the HR, and finally respiratory failure, which calls for ventilatory support (22-24). The present study demonstrated that compared with those obtained by PCV, the PIP, $\mathrm{P}_{\text {mean }}$ and Cst were significant improved, all which is beneficial to the respiratory system of patients, with PRVCV. The significant decrease in CVP and ELWI in the PRVCV group may be due to improved compliance and reduced thoracic pressure. The HR was also lower in the PRVCV compared with that in the PCV group, partly because the increased compliance of lung and thorax lead to an augmentation of the returned blood volume. No significant difference was observed in MAP, a parameter that is influenced by multiple aspects, including treatment interventions.

Apart from ABG, significant improvements were also observed in respiratory mechanics and hemodynamics. However, the SOFA score was not improved in the present study, due to two possible reasons: First, the present study only assessed the respiratory and cardiovascular systems, whereas the SOFA score encompasses a total of six systems $(25,26)$, and furthermore, an observation time of $6 \mathrm{~h}$ may not have been sufficient to improve the SOFA score. Therefore, a follow-up experiment with longer post-ventilation time is required. The present study was a prospective cohort study with a limited sample size, which may have affected the difference in outcome this was a limitation of the study. Additional randomized controlled trials may be helpful for comparing the two ventilation modes. It may be concluded that the PRVCV mode combines the advantages of VCV and PCV, and may provide stable tidal volume at the lowest possible peak airway pressure and MAP, and is a lung protective mode that may reduce the risk of barotrauma in patients with IAH or ACS.

\section{Acknowledgements}

Not applicable.

\section{Funding}

This study was supported by grants from National Nature Science Foundation of China (grant no. 81500351) and the Jiangsu Provincial Key Research and Development Program (grant no. BE2016721).

\section{Availability of data and materials}

The datasets used and/or analyzed during the present study are available from the corresponding author on reasonable request.

\section{Authors' contributions}

BW designed the study and wrote the manuscript. JY, JJ, XP and SS performed the experiments and analyzed the data. All authors read and approved the final manuscript.

\section{Ethical approval and consent to participate}

The present study was approved by the Medical Research Ethical Committee of Jiangsu University (Zhenjiang, China) and all subjects provided written informed consent. 


\section{Patient consent for publication}

Not applicable.

\section{Competing interests}

The authors declare that they have no competing interests.

\section{References}

1. Kirkpatrick AW, Roberts DJ, De Waele J,Jaeschke R, Malbrain ML, De Keulenaer B, Duchesne J, Bjorck M, Leppaniemi A, Ejike JC, et al: Intra-abdominal hypertension and the abdominal compartment syndrome: Updated consensus definitions and clinical practice guidelines from the world society of the abdominal compartment syndrome. Intensive Care Med 39: 1190-1206, 2013.

2. Arabadzhiev GM, Tzaneva VG and Peeva KG: Intra-abdominal hypertension in the ICU-a prospective epidemiological study. Clujul Med 88: 188-195, 2015.

3. Papavramidis TS, Marinis AD, Pliakos I, Kesisoglou I and Papavramidou N: Abdominal compartment syndrome-Intra-abdominal hypertension: Defining, diagnosing, and managing. J Emerg Trauma Shock 4: 279-291, 2011.

4. Smit M, Buddingh KT, Bosma B, Nieuwenhuijs VB, Hofker HS and Zijlstra JG: Abdominal compartment syndrome and intra-abdominal ischemia in patients with severe acute pancreatitis. World J Surg 40: 1454-1461, 2016.

5. Aghadavoudi O, Alikiaii B and Sadeghi F: Comparison of respiratory and hemodynamic stability in patients with traumatic brain injury ventilated by two ventilator modes: Pressure regulated volume control versus synchronized intermittent mechanical ventilation. Adv Biomed Res 5: 175, 2016.

6. Dion JM, McKee C, Tobias JD, Sohner P, Herz D, Teich S, Rice J, Barry ND and Michalsky M: Ventilation during laparoscopic-assisted bariatric surgery: Volume-controlled, pressure-controlled or volume-guaranteed pressure-regulated modes. Int J Clin Exp Med 7: 2242-2247, 2014.

7. Gruber PC, Gomersall CD, Leung P, Joynt GM, Ng SK, Ho KM and Underwood MJ: Randomized controlled trial comparing adaptive-support ventilation with pressure-regulated volume-controlled ventilation with automode in weaning patients after cardiac surgery. Anesthesiology 109: 81-87, 2008

8. Samantaray A and Hemanth N: Comparison of two ventilation modes in post-cardiac surgical patients. Saudi J Anaesth 5: 173-178, 2011

9. Barr J, Kishman CP Jr and Jaeschke R: The methodological approach used to develop the 2013 pain, agitation, and delirium clinical practice guidelines for adult ICU patients. Crit Care Med 41 (9 Suppl 1): S1-S15, 2013.

10. Jaipuria J, Bhandari V, Chawla AS and Singh M: Intra-abdominal pressure: Time ripe to revise management guidelines of acute pancreatitis? World J Gastrointest Pathophysiol 7: 186-198, 2016.

11. Hunt L, Frost SA, Hillman K, Newton PJ and Davidson PM: Management of intra-abdominal hypertension and abdominal compartment syndrome: A review. J Trauma Manag Outcomes 8 : 2,2014 .
12. Prasad GR, Subba Rao JV, Aziz A and Rashmi TM: The role of routine measurement of intra-abdominal pressure in preventing abdominal compartment syndrome. J Indian Assoc Pediatr Surg 22: 134-138, 2017.

13. Atema JJ, van Buijtenen JM, Lamme B and Boermeester MA Clinical studies on intra-abdominal hypertension and abdominal compartment syndrome. J Trauma Acute Care Surg 76: 234-240, 2014.

14. Dalfino L, Sicolo A, Paparella D, Mongelli M, Rubino G and Brienza N: Intra-abdominal hypertension in cardiac surgery. Interact Cardiovasc Thorac Surg 17: 644-651, 2013.

15. Díaz F, Erranz B, Donoso A, Salomon T and Cruces P: Influence of tidal volume on pulse pressure variation and stroke volume variation during experimental intra-abdominal hypertension. BMC Anesthesiol 15: 127, 2015.

16. Tiwari AR and Pandya JS: Study of the occurrence of intra-abdominal hypertension and abdominal compartment syndrome in patients of blunt abdominal trauma and its correlation with the clinical outcome in the above patients. World J Emerg Surg 11: 9, 2016.

17. Kyoung $\mathrm{KH}$ and Hong SK: The duration of intra-abdominal hypertension strongly predicts outcomes for the critically ill surgical patients: A prospective observational study. World J Emerg Surg 10: 22, 2015

18. Muturi A, Ndaguatha P, Ojuka D and Kibet A: Prevalence and predictors of intra-abdominal hypertension and compartment syndrome in surgical patients in critical care units at Kenyatta National Hospital. BMC Emerg Med 17: 10, 2017.

19. Rastogi P, Iyer D, Aneman A and D'Amours S: Intra-abdominal hypertension and abdominal compartment syndrome: Pathophysiological and non-operative management. Minerva Anestesiol 80: 922-932, 2014.

20. Zhao JG, Liao Q, Zhao YP and $\mathrm{Hu}$ Y: Mortality indicators and risk factors for intra-abdominal hypertension in severe acute pancreatitis. Int Surg 99: 252-257, 2014.

21. Verzilli D, Constantin JM, Sebbane M, Chanques G, Jung B, Perrigault PF, Malbrain M and Jaber S: Positive end-expiratory pressure affects the value of intra-abdominal pressure in acute lung injury/acute respiratory distress syndrome patients: A pilot study. Crit Care 14: R137, 2010.

22. Ortiz-Diaz E and Lan CK: Intra-abdominal hypertension in medical critically ill patients: A narrative review. Shock 41: 175-180, 2014.

23. Shaheen AW, Crandall ML, Nicolson NG, Smith-Singares E, Merlotti GJ, Jalundhwala Y and Issa NM: Abdominal compartment syndrome in trauma patients: New insights for predicting outcomes. J Emerg Trauma Shock 9: 53-57, 2016.

24. Kollias S, Stampolidis N, Kourakos P, Mantzari E, Koupidis S, Tsaousi S, Dimitrouli A, Atiyeh B and Castana O: Abdominal compartment syndrome (ACS) in a severely burned patient. Ann Burns Fire Disasters 28: 5-8, 2015.

25. de Freitas GR, da Fonseca-Neto OC, Pinheiro CL, Araújo LC, Barbosa RE and Alves P: Relationship between Sequential Organ Failure Assessment (SOFA) and intra-abdominal pressure in intensive care unit. Arq Bras Cir Dig 27: 256-260, 2014 (In English, Portuguese).

26. de Grooth HJ, Geenen IL, Girbes AR, Vincent JL, Parienti JJ and Oudemans-van Straaten HM: SOFA and mortality endpoints in randomized controlled trials: A systematic review and meta-regression analysis. Crit Care 21: 38, 2017. 